\title{
Diversity and Safety on Campus @ Western: Heterosexism and cissexism in higher education.
}

Nicole Asquith (Western Sydney University, Australia)

Tania Ferfolia (Western Sydney University, Australia)

Brooke Brady (Western Sydney University, Australia)

Benjamin Hanckel (Western Sydney University, Australia)

Corresponding author: Prof Nicole L. Asquith, School of Social Sciences and Psychology, Western Sydney University, Locked Bag 1797, Penrith NSW 2751, Australia.

Email: N.Asquith@westernsydney.edu.au

\begin{abstract}
Discrimination, harassment, and violence can mediate staff and students' experiences of education and work. While there is increasing knowledge about these experiences in primary and secondary education, very little is known about these experiences in higher education. This paper draws from landmark research that examines the interpersonal, educational, and socio-cultural perspectives that prevail about sexuality and gender diversity on an Australian university campus. In this paper we focus on three aspects of the broader research findings: the heterosexism and cissexism experienced by sexuality and gender diverse (SGD) students and staff at the university; their actions and responses to these experiences; and, the impact of these experiences on victims. The research demonstrates that although the university is generally safe, SGD students and staff experience heterosexist and cissexist discrimination, which can have negative ramifications on their workplace and learning experiences.
\end{abstract}

\section{Key Words}

Heterosexism; cissexism; discrimination; exclusion; university

\section{Introduction}

Over the last few years, there has been growing research interest in the experiences of sexuality and gender diverse staff and students in Australian higher education (Australian Human Rights Commission, 2017; Dau and Strauss, 2016; Ferfolja, 2010; Ferfolja and Hopkins, 2013; Ferfolja and Stavrou, 2015; Ferfolja and Ullman, 2017; Israel et al., 2017; Miller, 2017; Roffee and Waling, 2016; Waling and Roffee 2017, 2018). To date, much of this research has been qualitative, and based on interviews with students (and sometimes, staff) who identify as lesbian, gay, bisexual, transgender, intersex and/or queer (LGBTIQ). This paper reports on findings from mixed methods research conducted at Western Sydney University (Western). Diversity and Safety on Campus @ Western (Ferfolja et al., 2018), which is the first and only Australian study to collect both qualitative and quantitative data on heterosexism and cissexism experienced by sexuality and 
gender diverse (SGD) ${ }^{1}$ staff and students in a university context $(N=412)$. Additionally, it is the only study of its kind to also document the views of all staff and students (sexuality and gender diverse (SGD) and non-SGD) about sexuality and gender diversity, and their capacity to intervene in heterosexist and cissexist exclusion ${ }^{2}(N=2,395)$. This landmark research makes a significant contribution to the field through its exploration of the interpersonal, educational, and socio-cultural perspectives that prevail about sexuality and gender diversity on campus, and its examination of interventions in heterosexist and cissexist exclusion and the services available to support SGD individuals on campus. This paper focuses on three key areas of the overall project: sexuality and gender diverse staff and students' experiences of exclusion (at 12 months, since starting as a student or staff member at Western, and their most significant incident); their actions at the time of their most significant incident; and the consequences and impacts of heterosexist and/or cissexist exclusion. Before reporting on the research findings, it is critical to contextualise the research.

\section{Homonormativity in higher education}

Victims have long been ignored by scholars of crime, and it has only been in the latter half of the twentieth century that victims' experiences have been subject to the necessary theorisation central to developing evidence-based approaches (Rock, 2007). Initially, based on studies of extreme violent crime such as homicide, victims were framed as complicit in their victimisation, or that their actions precipitated their victimisation (von Hentig, 1940; Wolfgang, 1957). In additional to blaming victims for their experiences, this 'penal coupling' (Mendelsohn, 1963) of victims and offenders laid the groundwork for later theorising, which framed victims as 'targets' of crime. Yet, conversely, the structural coordinates of being targeted were largely unremarked and unremarkable until the growth in feminist scholarship in criminology in the 1980s. The attribution of blame, and failure to recognise the inequitable division of victimisation, led to the development of conservative theories of victimisation, which tended to place the onus on victims and their routine activities or lifestyle choices. Both routine activity theory (Cohen and Felson, 1979) and lifestyle theory (Hindelang et al., 1978) posit that it is the people and places encountered by victims that bring them into contact with offenders and victimisation. The implication is that that victims are best to avoid these criminogenic people and places if they are unable to harden themselves against being a target of crime. Central to these theories are concepts such as target (victim) attractiveness - in particular, their vulnerability - and capable guardianship. Yet, when the gaze was shifted from opportunistic street crime to crimes in the home and sub-criminal or civil offenses (such as discrimination and harassment), the structural and political effects of victimisation were foregrounded.

Early critical, Marxist, and feminist victimologists exposed the unequal divisions of victimisation, and the inadequacies of approaches that seek to harden targets or increase capable guardianship (Taylor et al, 1973; Smart, 1977). Rather than place the onus on victims to harden themselves against victimisation, or even more paternalistically, seek a guardian to intervene on their behalf, these alternative theories of victimisation seek to foreground the actions and behaviours of perpetrators as they reflect wider social and political norms. Rock (2007, p. 54) suggests that '[w]e have moved far away from simple stereotypes of vulnerability and victimisation, away from the

\footnotetext{
$1 \quad$ Approximately 500 different terms for gender and sexuality identity have been documented (Miller, 2017). Although not wishing to conflate or silence the range of identities, for reasons of practicality, the terms sexuality and gender diverse/diversity are used in this paper to include people of all sexualities and genders who do not identify as strictly heterosexual and cisgender. This nomenclature is discussed in more detail in the methods section.

The term, 'exclusion' is used throughout this paper as an umbrella term for diverse experiences of heterosexism and cissexism. These experiences range from microaggressions, bullying, harassment, and discrimination through to physical and sexual assault. In adopting this term, we do not wish to conflate the qualitatively different harms that may arise out of, for example, microaggressions and sexual assault. Where relevant, we document these differences and label the specific form of heterosexism or cissexism. However, it is important to note that sometimes verbal abuse can have more significant consequences for a victim than physical assault. It is therefore important not to minimise an experience just because it is not legislated as a crime. Where relevant - such as with regard to victims' reporting behaviours and actions after the incident—we make the distinction between criminal and sub-criminal behaviour.
} 
little old lady who represented Christie's "ideal victim" (1986), and towards a more nuanced appreciation of crime and its effects'. In considering the experiences of heterosexism and cissexism in higher education, and the variety of forms and places in which these experiences occur, we add to the growing critical feminist research on victimisation.

Some of the experiences we document in this research could be considered through the lens of 'hate crime' or prejudice related violence. According to this perspective - a perspective, importantly, that does focusses on the social and structural attributes of exclusionary violenceoutsiders are targeted individually for violence as part of a wider system of power that rewards the centre and punishes the margin. However, the concept is not without its problems; most particularly, the focus on crimes has led to the minimisation of the effects of sub-criminal behaviour, and in the conversion from theory to practice, this focus on criminal behaviour has concretised in hate crime statutes that enhance penalties. Asquith et al. (2019) also identify the critical ways in which the hate crime discourses of the global North are caught in a carceral logic that is unresponsive to the lived experiences of LGBTIQ+ people in the global South. Finally, while an appropriate lens for some experiences of heterosexism and cissexism, its operationalisation through identity fails to consider the ways that 'hate crime' is experienced between the intersections in identity. "'Hate crime" is a ... slippery and somewhat elusive notion whose conceptual and operational ambiguity raises thorny questions for those charged with responding to the forms of victimization and perpetration associated with the construct' (Chakraborti and Garland, 2012). As with Chakraborti and Garland (2012) we prefer to consider these experiences through the lens of iatrogenic, ontological and situational vulnerability (Bartkowiak-Théron et al., 2017). This approach enables us to consider the individual, social, and institutional aspects of victimisation, the intersections in vulnerability, and shared experiences across identities.

\section{Experiences of exclusion}

Although there has been growing societal acceptance and celebration of sexuality and gender diversity in Australia, this has not been well-reflected in its educational institutions. In schools, sexuality and gender diversity has been historically silenced, and both institutional and interpersonal exclusions towards sexuality and gender diverse individuals in schools have been reported (Ferfolja and Hopkins, 2013; Ferfolja and Stavrou, 2015; Ferfolja and Ullman, 2017; Harris and Jones, 2014). However, relatively little research has been conducted in Australia about the experiences of sexuality and gender diverse people engaged in the tertiary education sector (Israel et al., 2017; O'Shea et al., 2016). In fact, much of the literature about SGD individuals arises from the USA and UK, and indicates that 'homophobia on campus is endemic, with little evidence of real change over the past two decades' (Ellis, 2009, p. 726; Schmitz and Tyler, 2017). Sanlo and Espinoza (2012, p. 476) assert that 'LGBTIQ students are victimised at a far higher rate than other populations on campus, perhaps as much as four times more often than the general student population'. Considering the impact on life choices that tertiary education has on social, personal and professional development (Australian Human Rights Commission, 2017), this is a critical research gap that has only begun to be addressed.

Findings from recent Australian research which focused solely on the experiences of 264 lesbian, gay, bisexual and transgender (LGBT) students revealed that university campus climate was perceived to be hostile particularly towards transgender students who were most likely to experience discrimination (Dau and Strauss, 2016). The study found that more than half of the survey respondents did not disclose their sexuality or gender identity to others for fear of potential harassment, although two thirds of the participants considered their peers to be accepting of LGBT people. Sixteen per cent of respondents had experienced heterosexist or cissexist harassment or discrimination on campus, mostly from students, and nearly a quarter had witnessed such incidents. Interestingly, only 56 per cent felt comfortable reporting harassment to the university, although 82 per cent of the respondents did not know to whom they should report. Generally, the university was 
considered safe although transgender, non-binary, and gender non-conforming students felt concerned about safety when availing themselves of washrooms or when displaying visible LGBT identifiers. Critically, one fifth felt that responses to their sexuality and/or gender identity had resulted in disruption to their academic progression and one third felt it had impacted their ability to socialise at the university; almost 20 per cent felt they had been excluded from clubs or societies (Dau and Strauss, 2016, p. 20).

Similarly, Ellis' (2009) research, conducted across 42 universities in the United Kingdom, found that despite increasing equity agendas, many universities are not considered safe spaces by SGD students who are, or wish to be, visible about their identities. In fact, nearly a quarter of the students Ellis surveyed had been, on at least one occasion, the target of heterosexism or cissexism. Four out five experienced negative remarks, nearly half had been verbally harassed, and just over a quarter had been threatened with physical violence. Other kinds of exclusion experienced by SGD individuals on campus include, but are not limited to, being threatened; being pressured to remain silent about one's identity; being the recipient of written comments, 'jokes', anti-gay sentiment, general harassment and graffiti; being denied services; and being physically assaulted (see also Evans and Broido, 2002; Jayakumar, 2009).

International research also shows that lesbian, gay and bisexual students are also at a higher risk of sexual assault (Coulter et al., 2017; Coulter and Rankin 2017) and these events are more apparent for transgender individuals (Cantor et al, 2015; Griner et al., 2017; Harris and Linder, 2017; Marine, 2017). Marine (2017, p. 86) found that students who identify as transgender, genderqueer, questioning, or gender nonconforming (TGQN) 'experience[d] sexual violence on campus at a greater rate than cisgender women'. Dugan et al.'s (2012) study examined 91 transgender students' college experiences and found these students reported higher incidents of harassment, a lower sense of belonging, and less participation in engagement experiences (such as internships, mentoring or community service) when compared to their non-SGD peers (Tetreault et al., 2013). Similar negative experiences of transgender, genderqueer, and gender non-conforming students are described in the national report Change the Course (Australian Human Rights Commission, 2017), which focused on sexual harassment and assault across 39 Australian university campuses. This report demonstrated that these students are more vulnerable to sexual harassment and sexual assault, with 42 per cent reporting that they had been sexually harassed in a university setting (Australian Human Rights Commission, 2017, p. 42). Such findings are also well-reported in the international literature (Cantor et al., 2015; Coulter and Rankin, 2017; Marine, 2017; Tetreault et al., 2013).

Although most discrimination experienced by SGD students is played out by cisgender and/or heterosexual individuals or the institution (D’Augelli, 1992; Dwyer, 2011; Meyer, 2012), research conducted in Victoria, Australia, found that internal group politics could also cause concern for some SGD individuals on campus. Waling and Roffee (2017, p. 10) interviewed 16 LGBTQI+ identifying undergraduate students and found that 'subscribing to homonormativity, or problematically being too mainstream and conformist' resulted in feeling unwelcome by the LGBTQI+ university community. They also reported that this affected their interactions with support provisions such as queer spaces. The emerging Australian literature to date, suggests that SGD students' campus experiences can be highly problematic. Broader campus heterosexism and cissexism, silences and exclusions, or conflicting identity politics may create a difficult, complex, unsupportive, or even hostile environment.

While less is known about SGD tertiary staff experiences of heterosexism and cissexism, many LGBT employees fear discrimination in the workplace, including losing their position or having their identity used to impede their opportunities for success (Asquith, 1999; Brooks and Edwards 2009; Ferfolja, 2010; Willis 2009, 2011). Bilimoria and Stewart (2009, p. 86), reporting on research with academics, point to the: 
Everyday slights, harassment, intimidation, fears, exclusion, and discrimination experienced by LGBT faculty, including tokenism, stereotyping, increased visibility and scrutiny, isolation and boundary heightening, difficulties in the classroom ... constraints on choices of scholarship ... [and] perceived negative career consequences.

Clearly, many experiences of discrimination are subtle and less discernible microaggressions than overt injurious acts; as a result, they are often difficult to report or address because of their nebulous nature. It is also critical to note that none of the existing Australian studies have considered the experiences of SGD staff in higher education; nor do they consider non-SGD staff and students' perceptions, tolerance, and acceptance of sexuality and gender diversity.

\section{Consequences of heterosexism and cissexism}

Although campuses differ with regard to the heterosexism and cissexism experienced and the problem's extent, the potential for exclusion to occur can have serious ramifications on SGD individuals. For instance, despite relatively low levels of reported homophobia on campus, Ellis (2009) found that "it occurred frequently enough to have created a "climate of fear" whereby LGBT students deliberately act to conceal their sexual orientation/gender identity in order to avoid peer and/or institutional discrimination/harassment' (p. 734). Heterosexism and cissexism are considerably under-reported to either university management or external authorities such as the police (Ellis, 2009; Forbes-Mewett and McCulloch, 2016; Garvey, 2017) and this reflects broader trends of experiences in the public milieu (Fileborn, 2012; Miles-Johnson, 2013). As a result of either actual or potential exclusion, sexuality and gender diverse individuals often feel safer and more secure by remaining silent and invisible, and employing what Griffin $(1991,1992)$ terms in her US study of lesbian and gay educators, 'passing' and 'covering' strategies.

The perceived need to employ such protective strategies coupled with threats of potential and/or actual discrimination increases the risks for psychological distress, anxiety, and mental health issues such as depression and suicide ideation (Keuroghlian et al., 2014). Individuals may feel vulnerable or socially isolated; may have issues with self-esteem; may experience chronic stress or difficulties establishing intimate relationships and may demonstrate an unwillingness to seek support due to fear of disclosure and further discrimination (Fette et al., 2013; Sanlo and Espinoza, 2012). In Woodford et al.'s (2013) examination of intentional and unintentional microaggressions (such as hetero/cissexist jokes and phrases), positive associations between students hearing the phrase, 'that's so gay' and feelings of social isolation as well as corporeal effects such as headaches and stomach problems were identified. Moreover, other research has found that a negative microculture obstructed positive outcomes, perpetuated thoughts of leaving university, and impacted retention, academic progression and engagement (Dau and Strauss, 2016; Hong et al., 2016; Tetreault et al., 2013; Woodford and Kulick, 2015).

It is clear from this review of the existing research that there is much unknown about the experiences of SGD students; a lacuna even more pronounced in the case of SGD staff in higher education. The research reported here contributes much to the discussion about experiences of exclusion in higher education, and the necessary steps for greater inclusion of sexuality and gender diverse staff and students. Below we consider:

- What are the contexts of heterosexism and cissexism in higher education?

- How is heterosexism and cissexism experienced by SGD staff and students?

- What are the consequences of heterosexism and cissexism in higher education? 


\section{Methods}

Diversity and Safety on Campus @ Western employed a mixed-methods approach to collect data about safety and diversity on campus, particularly for SGD individuals. A university-wide, online survey, individual interviews, and a document (and website) audit were conducted. Prior to beginning the fieldwork, ethics for this research was sought and approved by the Western Sydney University Human Research Ethics Committee in mid-2016 (\#H11264). This paper reports only on the findings from the survey of Western's staff and students.

\section{The survey}

The online survey was based initially on the original Lesbian and Gay Anti-Violence Project's 'Report of Violence' form ${ }^{3}$, and adapted to the education environment. Additionally, scales from other similar studies - in particular, sexual violence on campus research from the US and the UKwere adapted to account for SGD experiences, as well as attitudes and perceptions to SGD. The Fear of Heterosexism scale (Fox and Asquith, 2015) was added to the survey to investigate how the fear of discrimination, harassment, and violence impact on staff and student experiences. The survey design is such that in future iterations, the questions are easily adapted to consider other diverse experiences on campus (such as ethnicity, faith, and (dis)ability). The survey was constructed in three parts:

- Part 1 included demographic questions and belief in diversity at the university;

- Part 2 included questions regarding staff and student experiences of feeling valued; this included perceived safety, bystander efficacy, awareness of LGBTIQ $^{4}$ issues, and feelings of responsibility to help SGD persons in need;

- Part 3 included questions regarding fear of heterosexism/cissexism ${ }^{5}$, and personal experiences of exclusion. Respondents were asked about their experiences in the last 12 months, since starting as a student or staff member at Western, and the most significant incident at Western.

Parts 1 and 2 were open to all staff and students. Part 3 was completed only by those respondents who identified as sexuality and/or gender diverse. Completion of all three parts of the survey took approximately 25 minutes. The majority of respondents - those who did not identify as SGD completed the survey in approximately 15 minutes.

The full survey included 48 items; some with a large number of individual sub-items. This paper reports on the results of 31 questions from Part 3 of the survey. These items collected data regarding:

- the nature of the hetero/cissexist incident(s)

- the perpetrator(s) and their perceived motivation

- the location

- the frequency of incidents

- types of injuries and other forms of harm caused by the incidents

- help seeking behaviours

3 The Lesbian and Gay Anti-Violence Project (AVP) was instrumental in developing the capacity for reporting heterosexist and cissexist violence in Australia. The primary role of the AVP was to take reports of violence from victims, act on their behalf with policing and criminal justice agencies, and to educate the community about heterosexist and cissexist violence.

$4 \quad$ Here, 'LGBTIQ' is used as this is the terminology used in this scale

5 In this paper it is not possible to report the Fear of Heterosexism/Cissexism. 
- the outcome of the incident(s) and satisfaction with those outcomes

Respondents were asked about all incidents in the last 12 months, all incidents since starting at Western, and then asked to document their most significant incident, where 'most significant' referred to an incident that has had the greatest impact on their life as a student or staff member of Western. A number of open ended text response questions provided respondents with opportunities to document their experiences of exclusion, harassment, discrimination and or violence, and any positive experiences as an LGBTIQ person at Western.

\section{Recruitment}

Participants were recruited to the survey via scheduled emails from the Vice-President of the university ${ }^{6}$, which encouraged staff and students to participate. The School of Social Sciences and Psychology's online research participation platform, $\mathrm{SONA}^{7}$ was also adopted to recruit psychology students. These 220 students completed the survey via SONA and received course credit in exchange for participation. Finally, a media campaign was devised by the University's marketing unit for use on TV screens on all campuses. All participants (other than SONA participants) had the opportunity to enter their details into a monthly draw to win a $\$ 25$ voucher.

\section{Data screening}

A total of 3,106 participants were recruited for the research's survey component. Extensive data screening was undertaken to ensure the quality of the data and subsequent confidence in analyses. First, data were screened on progress, such that participants who left the survey before completing the demographic information and initial questions regarding perceived safety on campus were excluded. After this round of exclusions, 2,408 respondents remained. Second, non-serious responses (8; such as those who identified their gender as 'attack helicopters') or poorcomprehension (4) were also excluded. Additional data cleaning was undertaken to re-categorise 'other' responses to existing variables where these existed and were appropriate (e.g., 'straight' or 'normal' in answer to a question on sexuality was recoded to 'heterosexual').

Problematically, there appeared to be an over-sampling of people who identified as asexual. It was identified through contradictory data that 198 of the 'asexual' respondents in fact identified as heterosexual. For example, participants who reported that they were anti-SGD, or had never heard of or met any SGD persons, or included text data about being 'straight' or 'normal', were assumed to have misreported and/or misunderstood the term, 'asexual'. ${ }^{8}$ Unfortunately, due to the survey's sequencing, any respondent who incorrectly indicated that they were anything other than cishet $^{9}$ were directed to Part 3 (designed to capture the lived experiences of sexuality and gender diverse staff and students). Hence, data collected from cishet respondents were removed from Part 3 of the survey. After all exclusions, data from a total of 2,395 respondents remained, including the 412 SGD respondents who completed Part 3 of the survey.

\section{About the survey participants}

While the focus in the paper is on the experiences of SGD staff and students, it is perhaps salutary to first understand the overall demographic of research respondents and the context in which this research was undertaken. First, it is critical to note that by and large, Western is a safe, harmonious,

\footnotetext{
$6 \quad$ Vice-President (People and Advancement)

Research participation system to manage undergraduate students' completion of mandatory research instruments. In replicating this survey, the researchers advise the inclusion of a glossary of terms.

'Cis' is the opposite to 'trans', and means 'on this side'. The terms cisgender, cishet, and cis men and cis women are used deliberately to foreground that the bodies (and identities) of the 'norm' (of heterosexual, and gender assigned at birth) are equally social and constructed.
} 
and inclusive institution known for its support of, and pride in, diversity. Western is a world-class university with a student population exceeding 40,000 which is spread across ten campuses. These campuses are located in the western regions of metropolitan Sydney, situated in an arch encompassing the north-west, west and south-west suburbs. The University is located in one of the most culturally, ethnically, and linguistically diverse regions of Australia and this is reflected in the university's community.

As to be expected of research located in a tertiary learning institution, survey responses are more heavily weighted towards students; that is there were more student $(1,980 ; 83 \%)^{10}$ than staff $(415$; $17 \%)^{11}$ participantsd - representing five and nine per cent of each population group at Western, respectively. Most respondents were under the age of $25(1,507 ; 63 \%)$. Twenty-five per cent of respondents identified as disabled, and 48 per cent of these respondents indicated that they were disabled by a mental health condition.

As discussed in the introduction to this paper, a decision was made by the research team to adopt the term, 'sexuality and gender diversity/diverse'. This aligns with similar umbrella nomenclature such as SOGI (sexual orientation and gender identity); however, the authors believe that sexuality is not a matter of orienting, and that gender is not just an identity. ${ }^{12}$ In the Australian context, the term, 'sexuality and gender diversity' also aligns with the policy language of 'cultural and linguistic diversity' (CALD). As noted in Table 1 below, respondents identified across four sexes, ten genders and 17 sexualities (including those who were 'questioning', and three different responses for heterosexual). If we were to be inclusive beyond a plus sign added to the common acronym, LGBTIQ $^{13}$, Western Sydney University's acronym would be LGBTIQQGQGNCGFHAPP-A. ${ }^{14}$ The term, 'sexuality and gender diversity' whilst easier to use than LGBTIQQGQGNCGFHAPP-A is not without its problems; most glaringly, it fails to acknowledge sex, and in future studies this will need to be amended to 'sex, sexuality and gender diversity'. As with CALD, it also can be used to denote (and conflate and make invisible the differences between) everyone who is not of the dominant culture. However, as noted above, even in the SGD populations at Western Sydney University there are cisgender heterosexuals ${ }^{15}$, which indicates that these terms can be much more than a mark between the powerful and the powerless, the centre and the margin.

Table 1: Respondent Sex, Gender, and Sexuality

\begin{tabular}{l|l|l} 
& $N$ & $\%$ \\
Sex $[n=2,394]$ & & \\
Female & 1,710 & 71.4 \\
Male & 677 & 28.3 \\
Intersex & 2 & 0.1 \\
Other & 5 & 0.2 \\
Gender $[n=2,390]$ & & \\
Female/Feminine & 1,660 & 69.5 \\
Male/Masculine & 664 & 27.8
\end{tabular}

10 At the time of the survey, there were 39,428 students enrolled at Western; this represents a response rate of five per cent.

11 At the time of the survey there were 2,620 staff working at Western, including full-time and part-time ongoing, contract and sessional staff; this represents a response rate of 16 per cent.

12 We also wanted to avoid reducing transgender people's gender to an 'identity' whilst cisgender people's gender remains just that.

13 Though, it is important to note that even this is disputed, with some organisations using only LGBT, or LGBTI, and others use a different order in the acronym, such as LGBTQI or GLBT(I)(Q)(+).

14 Lesbian, gay, bisexual, transgender, intersex, queer, questioning, gender queer, gender non-conforming, gender fuck, heterosexual, asexual, pansexual, and poly-amorous

15 In this study, participants who identified as intersex and poly-amorous also identified as being cisgender heterosexuals. 


\begin{tabular}{l|l|l} 
Transgender & 13 & 0.5 \\
Gender Queer & 19 & 0.8 \\
Gender Non-Conforming & 25 & 1.0 \\
Other & 9 & 0.4 \\
Sexuality $[n=2,337]$ & & \\
Heterosexual & 1,925 & 82.0 \\
Gay & 70 & 3.0 \\
Lesbian & 63 & 2.7 \\
Bisexual & 169 & 7.2 \\
Asexual & 49 & 2.1 \\
Pansexual & 49 & 2.1 \\
Questioning & 6 & 0.3 \\
Queer & 6 & 0.3
\end{tabular}

Approximately 18 per cent of overall respondents identified as sexuality and gender diverse. Of these 412 respondents, 41 per cent, 12 per cent, and 12 per cent identified as bisexual, asexual and pansexual, respectively. Conversely, only 17 percent and 15 per cent of Western's SGD survey respondents indicated that they identify as gay or lesbian, respectively. The frequency of each of the sexuality values is both statistically and culturally significant. Unlike previous community surveys of SGD communities - which are dominated by the responses from gay and lesbian cisgender participants (for example, in WTi3 (Hillier et al. 2010) 38 percent of young women, and 84 per cent of young men identified as same-sex attracted) - the sexuality diversity at Western marks an important 'change of times' where sexual fluidity is increasingly acknowledged and accepted. Similarly, while the majority of respondents identified as cisgender (97\%), a diverse range of gender identities were also reported, with more respondents identifying as gender queer $(0.8 \%)$ and gender non-conforming $(1 \%)$ than transgender $(0.5 \%)$.

\section{Diversity and safety on campus @ Western}

\section{Experiences of heterosexism and cissexism}

Understanding cishet staff and students' perceptions about the extent of heterosexist and cissexist exclusion on campus is critical for the strategic development of more inclusive and safer learning and work environments. When asked about the number of incidents experienced (heterosexist/cissexist talk, jokes, discrimination, physical assault and verbal abuse), respondents reported witnessing over 500 incidents in a typical month, which extrapolates to over 6,300 incidents a year. Of these, 7.5 per cent of witnessed incidents may constitute a crime under the Crimes Act (NSW) 1900. Some of these incidents are those reported by the 412 SGD respondents to the survey and detailed below. However, given the disparity between the number of incidents all participants reported witnessing and the number of reports of heterosexism and cissexism reported by SGD participants in this survey, it is likely that the experiences reported below are only indicative of actual numbers of heterosexist and/or cissexist incidents experienced on campus.

In the last 12 months (prior to completing the survey), 19 per cent ( $n=66)$ of SGD respondents personally experienced heterosexist and/or cissexist exclusion on campus ${ }^{16}$, with nearly 70 per cent of these incidents perpetrated by students. Over 28 per cent of these respondents experienced repeated and habitual hetero/cissexism, with 9 per cent unable to recount the number of incidents in the last 12 months, and a single respondent who experienced daily incidents. While one-off incidents can be life changing given the right circumstances, repeated acts of discrimination can

16 Respondents were asked: 'In the last 12 months at Western Sydney University, have you experienced exclusion, prejudice, discrimination, harassment or violence because of your [perceived] sexuality or gender identity?' 
result in ongoing and long term consequences (Cosgrove et al., 2017; Lereya et al., 2015; Rinehart et al., 2017). Additionally, 23 per cent $(n=81)$ and 15 per cent $(n=52)$ of SGD respondents reported witnessing and intervening, respectively, in incidents of heterosexism and/or cissexism in the last 12 months.

When the time frame is widened from the last 12 months to include all their time at Westernwhich could be 12 months or twenty years - the possible opportunities for heterosexist or cissexist encounters increase. ${ }^{17}$ In contrast to their experiences in the last 12 months, over twice as many SGD respondents (40\%; $n=353$ ) had experienced heterosexism and/or cissexism since starting at Western. The most common forms of heterosexism and cissexism were discrimination $(31 \%)$, harassment and/or bullying (26\%) and written or verbal abuse (13\%). Importantly, 23 per cent of these incidents may constitute a crime under the Crimes Act (NSW) 1900, and a further 57 per cent may constitute a civil offence under the Anti-Discrimination Act (NSW) 1977. Of the 353 respondents, 15 per cent had experienced more than four incidents, with six per cent $(n=21)$ experiencing more than 10 . The latter group of 21 respondents includes students, and as such, these $10+$ incidents have likely occurred in the three short years that most students attend the university.

\section{Most significant incident of heterosexism and cissexism}

In addition to their experiences in the last twelve months and since starting at Western, respondents were also asked to provide details of their most significant incident of heterosexism and/or cissexism. ${ }^{18}$ As can be seen in Table 2 below, discrimination (42\%) and harassment/bullying (32\%) continue to be the most common types of exclusion experienced by staff and students. In contrast, written and verbal abuse - the third most frequent form of exclusion since starting at Western - is less likely to be considered their most significant incident. While none of the results are statistically significant, it is important to note the key differences between staff and students. In particular, it is more common for students than staff to experience criminal acts of exclusion $(14.3 \% \mathrm{v} 6.9 \%$, respectively); likewise, it is more common for students than staff to report discrimination as their most significant incident $(46.4 \%$ v $34.5 \%)$.

In contrast to experiences since starting at Western, 74 per cent of respondents' most significant experience of exclusion may constitute a civil offence under the Anti-Discrimination (NSW) 1977, and only 12 per cent may constitute a crime. Of these 14 criminal incidents, there was only one case of sexual assault and one threat of violence (constituting less than $1 \%$ of experiences); in contrast, since starting at Western, there were six cases of sex assault (2.2\%), and 14 cases of threats of violence (14\%). Even general assault was nominated by respondents as the most significant at lower rates than since starting at Western $(6,5.6 \%$ v $176.1 \%$, respectively). This provides additional evidence of the contextual nature of victimisation; while many talk of a continuum of harm from verbal abuse through to homicide, when respondents are asked to record their most significant experience of exclusion, respondents are more likely to nominate a civil offence than a criminal offence. Perhaps discrimination, harassment and bullying are perceived by respondents not only as most significant but also more significant in terms of longevity, impact, effect, or consequences.

\footnotetext{
17 Respondents were asked: 'Please indicate which of the following incidents you have experienced since starting at Western Sydney University as a student or staff member. Please tick all that apply. Only report incidents of prejudice and/or discrimination based on gender and/or sexual identity: Written or verbal threats or abuse/hate mail;

Discrimination; Harassment and/or bullying; Physical assault without a weapon; Physical assault with a weapon; Sexual assault; Threat of physical or sexual assault; Property damage/vandalism; Theft/burglary; Other (please specify); None of the above'

18 Respondents were asked to 'tell us about your most significant experience of prejudice and/or discrimination', before being asked to indicate: 'Which of the following best describes the incident? Please tick ONE ONLY: Written or verbal threats or abuse/hate mail; Discrimination; Harassment and/or bullying; Physical assault without a weapon; Physical assault with a weapon; Sexual assault; Threat of physical or sexual assault; Property damage/vandalism; Theft/burglary; Other (please specify); None of the above'.
} 
Table 2: SGD experiences of exclusion — most significant: type of incident [ $\mathrm{n}=113$ (29 staff; 84 students)]

\begin{tabular}{l|l|l|l|l} 
& \multicolumn{2}{c}{ STAFF } & \multicolumn{3}{c}{ STUDENTS } \\
Discrimination & $N$ & $\%$ & $N$ & $\%$ \\
Harassment and/or bullying & 10 & 34.5 & 39 & 46.4 \\
Written or verbal abuse & 11 & 37.9 & 24 & 28.6 \\
Physical and/or sexual assault & 4 & 13.8 & 3 & 3.6 \\
Property damage/ vandalism & 2 & 6.9 & 5 & 6.0 \\
Threats of violence & 0 & 0.0 & 6 & 7.1 \\
Other & 0 & 0.0 & 1 & 1.2 \\
& 2 & 6.9 & 6 & 7.1
\end{tabular}

Of the 113 SGD respondents who provided details about their most significant incident of heterosexism or cissexism, 38 respondents $(34 \%)$ were physically or psychologically harmed during the incident. Forty-three per cent of those respondents reported that their injuries were minor (e.g. bruises/cuts, minor passing anxiety), 13 per cent reported that their injuries were serious (e.g. broken bones, major psychological stress/anxiety), and one respondent indicated that the harm caused was critical (e.g. critical psychological event resulting in hospitalisation). In addition to the single incident of physical assault with a weapon, respondents who had been injured also reported the use of fists/feet/body $(n=2)$, vehicle $(n=1)$, and bottle $(n=1)$. Eleven respondents answered 'other' when asked about the harm caused by their most significant incident, reflecting that the negative effects of these experiences are likely to be more complex than can be measured by strict severity categories. Responses included 'major depressive episode', 'persistent heart arrhythmia, stress, insomnia', 'reduced self-esteem and feelings of isolation', 'incident impacted on my depression', 'went to my car, had an anxiety attack and a mild breakdown', and 'trauma'.

Forty-four per cent of these reported incidents were ongoing, with the duration varying from a 'few weeks' to 'many years, 10-15 years'. As can be seen in Table 3 below, nearly half of the 46 respondents reported heterosexist and/or cissexist exclusion lasting a year or more, with 15 per cent of cases still ongoing at the time of the survey, and nine per cent lasting over five years.

Table 3: SGD experiences of exclusion - most significant: duration of ongoing incident [ $\mathrm{n}=46$ ]

\begin{tabular}{l|l|l} 
& $N$ & $\%$ \\
Less than a month & 3 & 6.5 \\
3 months & 14 & 30.4 \\
6 months & 4 & 8.7 \\
1 year & 2 & 4.3 \\
2-5 years & 9 & 19.6 \\
> 5 years & 4 & 8.7 \\
Ongoing & 7 & 15.2 \\
Unknown & 3 & 6.5
\end{tabular}

Whether ongoing or one-off, heterosexism and cissexism can change lives irrevocably. However, unlike one-off incidents, witnesses and victims of these forms of exclusion must manage the fall-out from each and every incident, in addition to the layered harm from repeated, habituated, normalised violence. As the literature illustrates, discrimination and exclusion can have long term consequences which vary in their duration and severity (Fette et al., 2013; Keuroghlian et al., 2014; Sanlo and Espinoza, 2012). The extent and breadth of such experiences is difficult to truly ascertain 
as individuals most frequently do not report such experiences. However, there is undoubtedly an emotional burden on victims that is difficult to quantify in terms of personal, professional, and academic costs to the individual and, potentially, a loss to the university as a result of student withdrawal from subjects and courses.

\section{Sites of exclusion}

Western Sydney University is a relatively safe place (Ferfolja et al., 2018); however, there are pockets and specific sites that, reflecting reported negative experiences, may be less safe for all staff and students, and unsafe for SGD staff and students. The table below, documents the location of SGD respondents' most significant incident of heterosexism or cissexism.

Table 4: SGD Experiences of Exclusion-Most significant: Location [ $n=141$ responses; $n=112$ respondents]

\begin{tabular}{l|l|l} 
& $N$ & $\%$ \\
On my way to university & 18 & 12.8 \\
On my home campus (please tell us where on campus) & 39 & 27.7 \\
On another Western Sydney University Campus (Please specify which & 10 & 7.1 \\
campus) & 34 & 24.1 \\
In my class/tutorial/lecture/seminar & 8 & 5.6 \\
In my office & 3 & 2.1 \\
On the Western Sydney University shuttle bus & 3 & 2.1 \\
On a placement with an outside organisation & 1 & 0.7 \\
On a placement with Western (e.g. summer internship) & 3 & 2.1 \\
At a social event organised by a club/society/work group of Western & 8 & 5.6 \\
Online: Email & 3 & 2.1 \\
Online: Twitter/Facebook etc. & 11 & 7.8 \\
Other &
\end{tabular}

Nearly 13 per cent of the most significant incidents reported by participants occurred outside of Western (i.e. on the way to campus), and are virtually impossible for the university to respond to beyond lobbying government for safer public transport. However, the vast majority (83\%) were in some way within the remit of the university at the time of the incident ${ }^{19}$, including the 30 per cent of respondents (24\% of responses) who indicated that the location of their most significant incident was their learning or teaching environment (class, tutorial, lecture, or seminar). This is a critical finding, as it highlights the important work that needs to occur within this space to make it more inclusive of diverse student experiences.

Additionally, 10 per cent of respondents indicated that their most significant experiences of heterosexism and cissexism occurred online via email and social media. Existing netiquette strategies may not be sufficient, and further training and guidelines for staff and students on ethical communication online may be required. However, outside of Western's online systems, the university can only role model what is expected; in the wider 'marketplace of ideas', the university has no power to regulate heterosexism and cissexism. It is well-known that the online sphere is

19 During the implementation of this research, and in response to the findings of the LGBTI Uni Guide (NSW Gay and Lesbian Rights Lobby et al., 2015), Western undertook a comprehensive review of its policies and practices specifically in relation to SGD students and staff, including the development of guidelines for responding to heterosexist and cissexist discrimination (Hayter-Falconer, 2017). The Diversity and Safety on Campus @ Western research project, endorsed and funded by the university, was included within the remit of this review. 
moving at a pace that is far too rapid and complex for the implementation of protective legislation. This is problematic as the impact of online harassment can be serious, particularly as it leaves the target with no 'safe space' (Schenk and Fremouw, 2012).

\section{Heterosexist/cissexist perpetrators}

As with similar research investigating heterosexism and cissexism, respondents reported that the majority of their most significant incidents were perpetrated by men only (52\%) or men acting in conjunction with women (18\%). What is more notable, however, is the frequency of women only perpetrators (24\%). Women's engagement with crime generally has been on the increase over the last 20 years (Carrington 2015), however, over this same time, community safety surveys have consistently reported much lower participation of women in heterosexist and cissexist violence (Asquith and Fox, 2012; Australian Human Rights Commission, 2017; NSW Attorney General's Department, 2001).

Of the 96 most significant incidents with an individual perpetrator(s), 56 per cent were perpetrated by people under the age of 24 years. This is unsurprising given the majority of these incidents occurred within the learning/teaching environment at a university with a youthful student population. What is more notable is that 29 per cent of these most significant incidents were perpetrated by staff or students — but most likely given the age ranges, staff — over the age of 40 . Just over 80 per cent of incidents were perpetrated in the one-on-one or two-against-one encounters so common to discrimination more generally (Button and DiClementi, 2001). Notably, however, in 13 of respondents' most significant incidents there were more than three perpetrators, and in five cases, more than five. It is difficult to stand one's ground, let alone respond safely when one is so outnumbered — whether a student or staff member.

\section{Responses to heterosexism and cissexism}

Many people think that they would know what they would do (or not) during an incident of exclusion and marginalisation. Some may have even pre-planned reactions to potential heterosexism or cissexism. However, one is more likely to have considered the latter of these hypothetical encounters if they identify as SGD. Too often, SGD people are expected to be 'out', and to be 'that person' who responds and reacts to each incident of heterosexism or cissexism; however, context is important and assessing the conditions for intervention and response is critical to the safety of SGD staff and students.

Table 5: SGD Experiences of Exclusion-Most significant: Action at time of incident $[n=122$ responses; $n=114$ respondents]

\begin{tabular}{l|l|l} 
& $N$ & $\boldsymbol{\%}$ \\
Ignored the perpetrator(s) & 57 & 59.4 \\
Verbally retaliated & 25 & 26.0 \\
Fled & 12 & 12.5 \\
Protect self & 8 & 8.3 \\
Hid & 3 & 3.1 \\
Other & 17 & 17.7
\end{tabular}

Sometimes, the best response is to ignore the behaviour; other times, protecting oneself is the most that can be achieved. Fleeing the perpetrator is also an affirmative protective strategy that ensures that the witness/victim finds safety. Table 5 illustrates that most respondents ignored the perpetrator(s) $(60 \%)$. Ignoring heterosexism may diminish the potential for a situation to inflame; 
yet, it also allows that behaviour to circulate as normative and normal. It is important to note that none of the 96 respondents physically retaliated, though 26 per cent did so verbally.

Only 16 per cent of those who experienced exclusion, prejudice, discrimination, harassment or violence at Western felt comfortable reporting their experience. When asked why they chose not to report their most significant incident of heterosexism or cissexism, respondents' reasons included: the incident was resolved; was too pervasive; they were concerned about consequences; they did not want to exacerbate the situation; they did not know what to do; they had experienced inadequate past responses; and that the experience was too minor. Reporting incidents of heterosexism or cissexism is difficult, yet this is compounded when one perceives that an experience does not warrant the attention of the University, was too pervasive, or that respondents felt that it would exacerbate the situation. Additionally, individuals may fear that reporting an incident may result in double discrimination, where the potentially supportive authority from whom one seeks redress is itself prejudiced and unlikely to respond positively.

Respondents deployed a range of self-help and help-seeking strategies after their most significant incident, though respondents were more likely to reach out to informal and/or familial support than official services and programs provided by the University, and in the wider community. While the numbers are small ( $n=19$ responses; $n=15$ respondents), it is notable that apart from partner/family (9), friends (8), peers, colleagues and workmates (10), the only other supports sought by respondents were from counsellors/psychologists (6), or a workplace supervisor (6), and five respondents pursued action through the University's formal complaints process.

The negative impacts of heterosexism and cissexism are wide-reaching and can adversely affect the wellbeing of individuals. Table 6 documents some of the consequences and effects of heterosexism and cissexism. These effects have been consolidated into five main categories: reduced sociality; modified behaviour; less productive; psychological distress; more political. It is important at the outset to note that 26 per cent of respondents' most significant incidents resulted in no significant effects or consequences. As a proportion of all responses, this represents only 8 per cent of the effects recorded in Table 6 below. The remaining 92 per cent of responses clustered around issues such as increased avoidance and self-harm behaviours, and decreased mental health and wellbeing, self-esteem and self-worth, engagement with LGBTIQ people and places, and academic achievement. In particular, 40 per cent of respondents indicated that their most significant incident resulted in psychological distress, with 15 per cent indicating that it made them more worried, stressed/anxious, or depressed (8\%), and 5 per cent reported feeling sad or bad about their sexuality or gender. Importantly, though, these psychological effects are not shared equally between staff and students. The proportion of staff experiencing worry, stress or anxiety was higher than that of students ( $21.4 \%$ v $13.2 \%$, respectively), and conversely, students reported higher levels of feeling bad or sad about their sexuality/gender than staff ( $9.3 \% \mathrm{v} 4.3 \%$, respectively). The only responses to the item 'Made you generally less likely to go out/go to public places/socialise' were from students $(7.4 \%)$.

Table 6: SGD Experiences of Exclusion-Most significant: Impact and consequences (consolidated categories) [n=114 responses]

\begin{tabular}{l|l|l|l|l} 
& STAFF & \multicolumn{2}{|l}{ STUDENTS } \\
No significant effects & $N$ & $\%$ & $N$ & $\%$ \\
Reduced sociality & 19 & 7.4 & 7 & 10.0 \\
Modified behaviour & 54 & 20.9 & 10 & 14.3 \\
Less productive & 23 & 8.9 & 6 & 8.6 \\
Psychological distress & 40 & 15.5 & 5 & 7.1 \\
& 100 & 38.8 & 30 & 42.9
\end{tabular}




\begin{tabular}{l|l|l|l|l} 
More political & 16 & 6.2 & 10 & 14.3 \\
Other & 6 & 2.3 & 2 & 2.9
\end{tabular}

Academically, the most significant incident impacted on students' course progress and assessment outcomes (2\%), and on staff and students' attendance (9\%), and taking time off from their studies/work (3\%). These incidents also impacted on respondents' psycho-social well-being, including socialising (6\%), and negative impacts on friendships and relationships (5\%). It is important to note that seven per cent of students and four per cent of staff hid or kept hiding their sexuality or gender as a consequence of their most significant incident. While 'passing' can help victims feel more in control of how they are perceived by others, and they may 'act straight' to avoid future incidents of heterosexism/cissexism, it is no guarantee that this is an effective safety strategy, and there is much evidence that it has detrimental effects of mental health and wellbeing (Herek et al., 1999; Herek, 2004; Herek and Garnets, 2007). Respondents also provided information about additional effects or consequences from their most significant incident of heterosexism and cissexism, with one respondent indicating that it led them to attempt suicide. While most of the consequences of respondents' most significant incident of heterosexism or cissexism are negative, it is critical to note that their experiences led 8 per cent of respondents to become more political in seeking change; however, this political activism was not shared equally between staff and students, with staff more likely than students to report that their most significant incident made them 'more political in seeking change' ( $12.9 \%$ v $5.4 \%$, respectively). This finding has been identified in other research examining the impact of exclusionary practices towards gender and sexuality diversity in the workplace (Dau and Strauss, 2016; Waling and Roffee, 2017).

\section{Concluding remarks}

Unlike the one dimensional 'ideal victim' (Christie, 1986), or even the unthinking victim who waltzes through their routine activities (Cohen and Felson, 1979) and lifestyles (Hindelang et al., 1978) without a care for their safety, our participants understood their individual vulnerability and understood that their experiences are structured and structuring of wide power relations within and outside of the university. While the university celebrates diversity-primarily in its cultural, linguistic, and religious forms - too often it has abrogated its responsibilities for creating a safe and inclusive environment for sexuality and gender diverse staff and students. Academic autonomy and free of expression are well lauded values of the university, but as we found, these values are neither neutral nor equally available to all.

The classroom, for both staff and students, was a 'hot spot' of exclusion requiring particular attention. Changing this environment changes the wider culture of the university, especially when there is an explicit link between the values of diversity and inclusion and graduate/work outcomes. Changing the classroom environment, however, cannot be the sole responsibility of individual SGD staff and students given the individual, academic, and social costs that come with intervening and responding to heterosexism and cissexism. However, using the language of routine activity theory, at the very least, we may be able to increase the capacity of bystanders (other students and staff) to be capable guardians. Cishet participants clearly indicated that they are ready and willing to intervene in heterosexism and cissexism; but the experiences of SGD staff and students reported here also clearly show that these willing guardians either cannot recognise heterosexism and cissexism, or do not have the skills to intervene. Adding a topic about sexuality and gender diversity to the curriculum (usually, in week 11 of the semester) does little to embed an applied practice of cultural capability, or even students' and staff bystander capacity to intervene. Addressing the routine activity and lifestyle attributes of heterosexist and cissexist exclusion is not enough given it individualises a problem that is social and structural. As such, responses to heterosexism and cissexism must also address the social and structural layers of the individual 
experiences reported in this paper; which is a task wholly unsuitable to the existing theories of victimisation.

While the focus has been on hate crimes in the last 20 years, it should be remembered that heterosexism and cissexism are not always overt or criminal. As noted by our participants, heterosexism and cissexism often involve 'everyday exterminabilities' (Hage, 2006) and microaggressions (such as rude stares, avoidance, derogatory comments, dismissal of opinions and so on). The accretion of everyday micro-aggressions is not easy to 'get over' or to ignore, and creates a sense that SGD people are not welcome - are not in the right place. According to routine activity and lifestyle theories, our staff and students should be more careful about the places they transit, and seek out safer ways to get to where they want to go. Given that the heterosexism and cissexism experienced by our participants extend beyond the gates of our campuses, if we were to accept the warnings to avoid criminogenic people and places, there would be few places SGD staff and students are safe - even the family home may be pathogenic and a site of violence and exile (Asquith et al, 2018).

As reported herein, heterosexism and cissexism often have a negative impact on the targeted individual and when not addressed, these behaviours can become normalised and accepted. Allowing such events to circulate without intervention does nothing to prepare students for future careers, devalues the learning experience of SGD students, and makes the working lives of staff intolerable. As tertiary institutions develop the next generation of leaders, thinkers, and professionals, it is incumbent on them to prepare graduates to work with diversity to ensure inclusive and equitable practices. Lack of awareness of diversity, of cultural capability skills, and of confidence in bystander intervention (Ferfolja et al., 2018) can be addressed by integrating knowledge within course curricula, assessing that knowledge, and embedding that knowledge in graduate learning outcomes. Similarly, skills and understandings can be integrated into already existing induction training and professional development opportunities for staff to build capacity for support. The experiences of heterosexism and cissexism reported in this research and outlined in this paper demonstrate that ongoing work is required to develop proactive strategies and policies that enhance the university experience for SGD people. Moreover, any response to increase the inclusion of SGD staff and students in the tertiary sector will have flow-on effects by rolemodelling inclusion to the university's constituency (internal, community, and stakeholders) and by providing all students with graduate-ready skills such as cultural capability. This is critical considering the diverse nature of the workforce and the global flows of workers requiring social flexibility and nuanced understandings of difference.

It is important to remember that heterosexism and cissexism hurt everyone by their limiting constructions on how individuals 'do' their gender and sexuality identity and expression (Sedgwick, 1990). As illustrated above, for SGD individuals, heterosexist and cissexist exclusion can affect professional, academic, and personal well-being. With approximately 18 per cent of Western's survey respondents in this study indicating that they do not identify as cishet, the imperative to provide an inclusive and safe climate for SGD individuals cannot be overstated and can ameliorate risk management endeavours. Additionally, with the general reduction in tertiary enrolments across the Australian sector and on-going government funding cuts, carefully considered strategies may support the recruitment and retention of SGD students. As we indicated at the outset, very little research has been done in this field in relation to the tertiary sector in the Australian context; more is required to enable universities to develop strategic, long term approaches to ensuring equity and inclusion for all in the sector.

\section{References}

Anti-Discrimination Act (NSW) 1977 
Asquith, NL (1999) Sexuality at work. New Zealand Journal of Industrial Relations 24(1): 1-24.

Asquith NL, Dwyer, A, and Simpson, P (2018) A queer criminal career, Current Issues in Criminal Justice, 29(2): 167-180

Asquith, NL and Fox, C (2012) Be Proud Tasmania. Report, Working It Out, TasCHARD, Tasmanian Gay and Lesbian Rights Group, Hobart. DOI: 10.13140/RG.2.1.2988.1045

Asquith NL, Panfil V, and Dwyer, A (2018) Queer(y)ing justice. In Robinson, C (ed), Handbook of Social Justice in Criminal Justice. London and New York: Routledge, forthcoming.

Australian Human Rights Commission (2017) National report on sexual assault and sexual harassment at Australian universities. Report, AHRC, Canberra.

Bartkowiak-Théron, I, Asquith, NL, and Roberts, KA (2017) Vulnerability as a contemporary challenge for policing. In: Asquith, NL, Bartkowiak-Théron, Ai and Roberts, K (eds), Policing Encounters with Vulnerability. London: Palgrave, pp. 1-23.

Bilimoria, D and Stewart, AJ (2009) 'Don't ask, don't tell': The academic climate for lesbian, gay, bisexual, and transgender faculty in science and engineering. NWSA Journal 21(2): 85-103.

Brooks, AK and Edwards, K (2009) Allies in the workplace: Including LGBT in HRD. Advances in Developing Human Resources 11(1): 136-149.

Button, SB and DiClementi, JD (2001) Sexual identity management strategies: An exploration of antecedents and consequences. Sex Roles 45(5-6): 321-336.

Cantor, D, Fisher, B, Chibnall, S, et al (2015) Report on the AAU campus climate survey on sexual assault and sexual misconduct. Report, Westat, Maryland, USA.

Carrington, K (2015) Feminism and Global Justice: New directions in critical criminology. Abingdon, UK: Routledge.

Chakraborti, N and Garland J (2010) Reconceptualizing hate crime victimization through the lens of vulnerability and 'difference', Theoretical Criminology, 16(4): 499-514.

Christie, N (1986) The Ideal Victim. In: Fattah, EA (ed), From Crime Policy to Victim Policy. London: Macmillan, pp. 17-30.

Cohen, L and Felson, M (1979) Social change and crime rate trends: A routine activity approach. American Sociological Review, 44(4): 588-608.

Cosgrove, HE, Nickerson, AB and De Lucia, J (2017) Past peer victimization and current adult attachment in college students. Journal of College Counseling 20(1): 22-36

Coulter, RWS, Mair, C, Miller, E, et al (2017) Prevalence of past-year sexual assault victimization among undergraduate students: Exploring differences by and intersections of gender identity, sexual identity, and race/ethnicity. Prevention Science 18(6): 726-736.

Coulter, RWS. and Rankin, SR (2017) College sexual assault and campus climate for sexual- and gender-minority undergraduate students. Journal of Interpersonal Violence. Epub ahead of print 15 March 2017. DOI: https://doi.org/10.1177/0886260517696870. 
D'Augelli, AR (1992). Lesbian and gay male undergraduates' experiences of harassment and fear on campus. Journal of Interpersonal Violence 7(3): 383-395.

Dau, D and Strauss, P (2016) The Experience of lesbian, gay, bisexual, and trans students at The University of Western Australia: Research report 2016. Report, Equity and Diversity, The University of Western Australia, Perth.

Dugan, JP, Kusel, ML, and Simounet, DM (2012) Transgender college students: An exploratory study of perceptions, engagement, and educational outcomes. Journal of College Student Development 53(5): 719-736.

Dwyer, A (2011) Policing lesbian, gay, bisexual and transgender young people: A gap in the research literature. Current Issues in Criminal Justice 22(3): 415-433.

Ellis, SJ (2009) Diversity and inclusivity at university: A survey of the experiences of lesbian, gay, bisexual and trans (LGBT) students in the UK. Higher Education 57(6): 723-739.

Evans, NJ and Broido, EM (2002) The experiences of lesbian and bisexual women in college residence halls: Implications for addressing homophobia and heterosexism. In: Cramer, EP (ed), Addressing Homophobia and Heterosexism on College Campuses. Binghamton, NY: Harrington Park Press, pp. 29-42.

Ferfolja, T (2010) Lesbian teachers, harassment and the workplace. Teaching and Teacher Education 26(3): 408-414.

Ferfolja, T., Asquith, N.L., Brady, B., and Hanckel, B (2018) Diversity and Safety on Campus @ Western. Report to Western Sydney University, Sydney.

Ferfolja, T and Hopkins, L (2013) The complexities of workplace experience for lesbian and gay teachers. Critical Studies in Education 54(3): 311-324.

Ferfolja, T and Stavrou, E (2015) Workplace experiences of Australian lesbian and gay teachers: Findings from a national survey. Canadian Journal of Educational Administration and Policy 173: 113-138.

Ferfolja, T and Ullman, J (2017) Gender and sexuality diversity and schooling: progressive mothers speak out, Sex Education: Sexuality, Society and Learning, 17(3): 348-362.

Fileborn, B (2012). Sexual violence and gay, lesbian, bisexual, trans, intersex, and queer communities. Filesheet, Australian Centre for the Study of Sexual Assault, Melbourne, July.

Forbes-Mewett, H and McCulloch, J (2016) International students and gender-based violence. Violence Against Women 22(3): 344-365.

Fox, C and Asquith, NL (2015) Measuring the tangible fear of heterosexist violence. Journal of Interpersonal Violence. Epub ahead of print 25 November 2015.DOI: 10.1177/0886260515614279.

Griffin, P (1991) Identity management strategies among lesbian and gay educators. Qualitative Studies in Education 4(3): 189-202.

Griffin, P (1992) From hiding out to coming out: Empowering lesbian and gay educators. Journal of Homosexuality 2(3/4): 167-195. 
Griner, SB, Vamos, CA, Thompson, EL, et al (2017) The intersection of gender identity and violence: Victimization experienced by transgender college students. Journal of Interpersonal Violence. Epub ahead of print 8 August 2017. DOI: https://doi.org/10.1177/0886260517723743.

Hage, G (2006) On everyday exterminability (Keynote Speech). In: Everyday Multiculturalism Conference, Macquarie University, Sydney, 26-28 September 2006.

Harris, A and Jones, T (2014) Trans teacher experiences and the failure of visibility. In: Harris, A and Gray, EM (eds) Queer teachers, identity and performativity. Basingstoke, UK: PalgraveMacmillan.

Harris, JC and Linder, C (eds) (2017) Intersections of Identity and Sexual Violence on Campus. Centering minoritized students' experiences. Virginia: Stylus Publishing.

Hayter-Falconer, M (2017) Discrimination, Harassment, Vilification and Victimisation Prevention Guidelines (23 Feb 2017). Penrith: Western Sydney University.

Herek, GM (2004). Beyond 'homophobia': Thinking about sexual prejudice and stigma in the twenty-first century, Sexuality Research and Social Policy, 1(2): 6-24.

Herek, GM, and Garnets, L (2007). Sexual orientation and mental health, Annual Review of Clinical Psychology, 3: 353-375.

Herek, GM, Gillis, JR, and Cogan, JC (1999). Psychological sequelae of hate-crime victimization among lesbian, gay, and bisexual adults, Journal of Consulting and Clinical Psychology, 67(6): 945-951

Hillier, L, Jones, T, Monagle, M, et al (2010) Writing Themselves In 3 (WTi3): The third national study on the sexual health and wellbeing of same sex attracted and gender questioning young people. Report, Australian Research Centre in Sex, Health and Society, La Trobe University, Melbourne.

Hindelang, MS, Gottfredson, M and Garofalo, J (1978) Victims of Personal Crime: An empirical foundation for a theory of personal victimization. Cambridge, Mass.: Ballinger.

Hong, JS, Woodford, MR, Long, LD, and Renn, KA (2016) Ecological covariates of subtle and blatant heterosexist discrimination among LGBQ college students. Journal of Youth Adolescence 45(1): 117-131.

Israel, M, Skead, N, Heath, M, et al (2017) Fostering 'quiet inclusion': Interaction and diversity in the Australian law classroom. Journal of Legal Education 66(2): 332-356.

Jayakumar, UM (2009). The invisible rainbow in diversity: Factors influencing sexual prejudice among college students. Journal of Homosexuality 56(5): 675-700.

Keuroghlian, AS, Shtasel, D, and Bassuk, EL (2014) Out on the street: A public health and policy agenda for lesbian, gay, bisexual, and transgender youth who are homeless. American Journal of Orthopsychiatry 84(1): 66-72.

Lereya, ST, Copeland, WE, Costello, EJ, and Wolke, D (2015) Adult mental health consequences of peer bullying and maltreatment in childhood: Two cohorts in two countries. Lancet Psychiatry 2: 524-31. 
Marine, SB (2017) For Brandon, for justice. Naming and ending sexual violence against trans* college students. In: Harris, JC and Linder, C (eds) Intersections of Identity and Sexual Violence on Campus. Centering minoritized students' experiences. Virginia: Stylus Publishing, pp. 83-100.

Mendelsohn, B (1963) The origin of the doctrine of victimology. Excerpta Criminologica 3: 23945

Meyer, D (2012) An intersectional analysis of lesbian, gay, bisexual, and transgender (LGBT) people's evaluations of anti-queer violence. Gender and Society 26(6): 849-873.

Miles-Johnson, T (2013) LGBTQ variations in crime reporting: How sexual identity influences decisions to call the cops. Sage Open 3(2): 1-15.

Miller, sj (2017) Trans*+ing classrooms and schools: The pedagogy of refusal as mediator for learning under a 'Trump' regime. Presentation, Western Sydney University, Parramatta South Campus, December 18, 2017.

NSW Gay and Lesbian Rights Lobby, Star Observer, Out for Australia, Organisation Intersex International, and Transgender Victoria (2015) Australian LGBTI Uni Guide. Report, NSW GLRL, Start Observer, OfA, OII, and Transgender Victoria, Sydney.

O'Shea, S, Lysaght, P, Roberts, J, and Harwood, V (2016) Shifting the blame in higher education social inclusion and deficit discourses. Higher Education Research and Development 35(2): 332336.

Rinehart, SJ, Espelage, DL, and Bub, KL (2017) Longitudinal effects of gendered harassment perpetration and victimization on mental health outcomes in adolescence. Journal of Interpersonal Violence. Epub ahead of print 21 August 2017. DOI: https://doi-org.ezproxy.uws.edu.au/10.1177/ 0886260517723746.

Rock, P (2007) Theoretical perspectives on victimisation. In: Walklate, S (ed), Handbook of Victims and Victimology. Cullompton: Willan, pp. 37-54

Roffee, JA and Waling, A (2016) Rethinking microaggressions and anti-social behaviour against LGBTIQ+ youth. Safer Communities, 15(4): 190-201

Sanlo, R and Espinoza, L (2012) Risk and retention: Are LGBTQ students staying in your community college? Community College Journal of Research and Practice 36(7): 475-481.

Schenk, AM and Fremouw, WJ (2012) Prevalence, psychological impact, and coping of cyberbully victims among college students. Journal of School Violence 11(1): 21-37.

Schmitz, RM and Tyler, KA (2017) LGBTQ+ young adults on the street and on campus: Identity as a product of social context. Journal of Homosexuality. Epub ahead of print 12 April 2017. DOI: 10.1080/00918369.2017.1314162.

Sedgwick, E (1990) Epistemology of the Closet. Berkely, CA: University of California Press.

Smart, C (1977) Women, Crime and Criminology: A Feminist Critique. London: Routledge and Kegan Paul.

Taylor, I, Walton, P and Young, J (1973) The New Criminology. London: Routledge and Kegan Paul. 
Tetreault, PA, Fette, R, Meidlinger, PC and Hope, D (2013) Perceptions of campus climate by sexual minorities. Journal of Homosexuality 60(7): 947-964.

von Hentig, H (1940) Remarks on the interaction of perpetrator and victim. Journal of Criminal Law and Criminology 31: 303-9.

Waling, A and Roffee, JA (2017) Knowing, performing and holding queerness: LGBTIQ+ student experiences in Australian tertiary education. Sex Education 17(3): 302-318.

Waling, A., and Roffee, J (2018) Supporting LGBTIQ+ students in higher education in Australia: Diversity, inclusion and visibility. Health Education, forthcoming (accepted 5 February 2018).

Willis, P (2009) From exclusion to inclusion: Young queer workers' negotiations of sexually exclusive and inclusive spaces in Australian workplaces. Journal of Youth Studies 12(6): 629-651.

Willis, P (2011) Laboring in silence young lesbian, gay, bisexual, and queer-identifying workers' negotiations of the workplace closet in Australian organizations. Youth and Society 43(3): 957-981

Wolfgang, MF (1957) Victim precipitated criminal homicide. Journal of Criminal Law and Criminology 48(1): 1-11.

Woodford, MR, Howell, ML, Kulick, A, and Silverschanz, P (2013) 'That's so gay': Heterosexual male undergraduates and the perception of sexual orientation microaggressions on campus. Journal of Interpersonal Violence 28(2): 416-435.

Woodford, M and Kulick, A (2015) Academic and social integration on campus among sexual minority students: The impacts of psychological and experiential campus climate. American Journal of Community Psychology 55(1): 13-24. 